\title{
LA "GENERIZACIÓN" DE LA CIUDADANÍA. APUNTES SOBRE EL ROL DE LA DIFERENCIA SEXUAL EN EL PENSAMIENTO FEMINISTA*
}

\author{
Yanira Zúñiga Añazco**
}

\section{RESUMEN}

Este trabajo analiza la relación entre género y ciudadanía a la luz del debate feminista sobre el rol de la diferencia sexual en la construcción del sujeto político. A los efectos, se examinan algunos de los aspectos centrales de la teorización feminista en torno a la dicotomía público-privado y al Estado, explorando sus contradicciones y alcances prácticos.

$$
\text { DEMOCRACIA - GÉNERO - PARIDAD }
$$

The "genderization" of citizenship. Notes regarding the role of gender in feminist thought

\begin{abstract}
This paper examines the connection between gender and citizenship in light of feminist debate regarding the role of gender difference in the building of the political individual. For these purposes, some of the central aspects of feminist theory will be considered, especially those surrounding the public-private dichotomy, and the State, examining their contradictions and practical range.
\end{abstract}

DEMOCRACY - GENDER - PARITY

* Este trabajo forma parte del Proyecto FONDECYT de iniciación, No 11080280, cuyo título es Género, cuotas y paridad. Análisis de sus interrelaciones, similitudes y diferencias y del que la autora de este artículo es su investigadora responsable.

** Abogada, Doctora en Derecho, Profesora de Derecho Constitucional y Derecho Internacional Público en la Universidad Austral de Chile, Valdivia, Chile. yzuniga@uach.cl

Artículo recibido el 27 de agost de 2009 y aceptado para su publicación por el Comité Editorial el 26 de octubre de 2009. 


\section{Planteamiento del problema}

$\mathrm{E}$ n tiempos recientes hemos sido testigos del acceso de algunas mujeres a los puestos de representación popular más importantes a nivel estatal. Sin duda, ello refleja la ocurrencia de un cambio cultural de proporciones y, en este sentido, no deja de ser alentador. Con todo, el club de jefas de Estado (y/o Jefas de Gobierno) sigue siendo exiguo en comparación a su homólogo masculino, ${ }^{1}$ y el porcentaje mundial de presencia femenina en los distintos parlamentos no sobrepasa el $18 \% .^{2}$ Si se comparan tales cifras con un porcentaje de electrices que sobrepasa el $50 \%$ del electorado, la disonancia es evidente.

Hasta hace poco tal asimetría inquietaba poco o nada a las ciencias sociales ${ }^{3}$ y al Derecho. Me atrevería a decir, incluso, que era vista como expresión de la "normalidad de las cosas". Con el tiempo esta aparente normalidad ha devenido una suerte de patología de la democracia a la que, al menos en el nivel comparado, se ha aplicado un crisol de medidas estatales destinadas a aumentar la participación femenina en la esfera de la toma de decisiones políticas. De esta manera, se ha producido una transición acelerada desde una (supuesta) indiferencia respecto de las vinculaciones entre género y ciudadanía a una suerte de "generización" de la ciudadanía cuyos efectos teóricos han sido pocos explorados.

En este trabajo sostendré, como primera hipótesis, que la noción de género ha trazado un puente entre la teoría feminista y el Derecho que permite trasladar al dominio jurídico una teorización que, hasta ahora, ha permanecido ajena al dominio jurídico. Como segunda hipótesis coligada, afirmaré que, particularmente en lo relativo al rol de la diferencia sexual en la construcción de la ciudadanía, la teorización feminista está lejos de ser homogénea, lo que provoca que el fenómeno de "generización de la ciudadanía” tenga, en algunos casos, ribetes paradójicos o contradictorios. Algunos de estos aspectos paradójicos serán estudiados en este trabajo, tomando como eje la discrepancia del pensamiento feminista en torno al rol de la diferencia sexual.

${ }^{1}$ Hasta 2006, de 191 estados soberanos sólo 11 registraban una mujer en las calidades de Jefe de Estado o Jefe de Gobierno. Vid. Unión Interparlamentaria. Les femmes en politique: 60 ans en rétrospective (donnés valables au 01.02.2006), disponible en formato pdf en http://www.ipu.org/pdf/publications/wmninfokit06_fr.pdf, fecha de revisión 16.12.07 (existe versión en inglés).

${ }^{2}$ Fuente: Unión Interparlamentaria http://www.ipu.org/english/home.htm

${ }^{3}$ La perspectiva de género en las ciencias sociales como en general en las otras ciencias tiene su carta de nacimiento en los años 60 y 70 con los llamados estudios feministas o de la mujer. En el caso francés, como lo recuerda Françoise Gaspard, una de las obras precursoras en esta materia ha sido la investigación de Maurice Duverger titulada La participation des femmes à la vie politique aparecida en 1955 y cuya elaboración fue encomendada por la Comisión de la condición de la Mujer de Naciones Unidas con ocasión de la adopción de la convención de Naciones Unidas sobre derechos políticos de la mujer de 1952. Véase Gaspard, F. Les travaux sur le vote et l'éligibilité. La situation française, Coloquio "Genre et politique", organizado por la Asociation Française de Sciencies Politiques, 30 y 31 de mayo de 2002, textos disponibles en el sitio de la AFSP http://www.afsp.msh-paris.fr/, en formato electrónico PDF, fecha de revisión 26/07/09. 


\section{La Diferencia SeXual en la historia Del feminismo. Feminismo de la} IGUALDAD VS. FEMINISMO DE LA DIFERENCIA

Como señalé antes, el discurso justificatorio de las medidas de potenciación de participación política femenina es un discurso que proviene fundamentalmente del feminismo. Ha sido éste, tanto en sus vertientes práctica como teórica, el que ha encabezado de manera temprana la problematización de la exclusión de las mujeres de la ciudadanía a través de su marginación del sufragio y, más tardíamente, la denuncia de la construcción de una ciudadanía femenina incompleta centrada en la virtualidad del derecho a ocupar cargos públicos.

Aunque el feminismo es hijo de la modernidad y surge como una contestación al déficit de universalidad prometido por la revolución francesa, a poco andar va a demostrar sus discrepancias en torno al rol de la diferencia sexual en la construcción de la ciudadanía. En su libro La ciudadana paradojal. Las feministas francesas y los derechos del hombre", ${ }^{4}$ la historiadora estadounidense Joan Scott despliega una verdadera radiografía de la permanente oscilación del feminismo francés entre la reivindicación del universalismo republicano y el rescate de la diferencia. Al mismo tiempo, su análisis revela que gran parte del edificio arquitectural de la modernidad se vertebra, de manera consciente, sobre la exclusión femenina. Según Scott, en Francia han coexistido dos universalismos, uno de los derechos naturales y otro de la diferencia sexual. Este último habría prevalecido sobre el primero suponiendo a las mujeres incapaces de ejercer los derechos políticos y transformando al individuo masculino en su verdadero individuo abstracto. Scott explica que en el contractualismo clásico la dicotomía hombre/mujer es vista como una concesión necesaria a la "naturaleza" y no como una contradicción a las pretensiones universalistas del republicanismo francés. ${ }^{5}$

Así las cosas, el dilema permanente del feminismo ha sido cómo plantear la cuestión de la diferencia de sexo sin reproducir los términos sobre los cuales la exclusión de las mujeres ha sido primariamente formulada. Dicho de otra manera, cómo reivindicar el cumplimiento de la promesa contenida en el universalismo abstracto sin dejar de apelar a la "particularidad sexual".

En los inicios del feminismo, la confianza en las posibilidades de ensanchamiento e inclusión del modelo universalista apaciguan en buena medida este dilema, permitiendo

\footnotetext{
${ }^{4}$ Scott, Joan W.: "La citoyenne paradoxale. Le féministes françaises et les droits de l'homme", Biblioteque Albin Michel Histoire, París, 1998.

${ }^{5}$ Cfr. Scott, J., "La citoyenne paradoxale. Le féministes françaises et les droits de l'homme", Biblioteque Albin Michel Histoire, París, 1998, pp. 10 y 11. En el mismo sentido, Carole Pateman postula que la exclusión femenina fue un presupuesto del pensamiento contractualista clásico y que, en alguna medida, esa exclusión se mantiene en el pensamiento neocontractualista contemporáneo. En su conocido texto el contrato sexual, Pateman sugiere que hay una implicación entre contrato social y patriarcado y que en esta implicación descansa la distinción entre las esferas privada y pública, al punto que la "antinomia público/ privado es otra expresión de natural/civil y de mujeres/varones". En este esquema "la diferencia sexual es una diferencia política [...] es la diferencia entre la libertad y la sujeción Pateman, C. El contrato sexual, Arthropos, Barcelona, 1995, p. 15.
} 
el desarrollo, casi sin contrapunto, de un feminismo de corte liberal-ilustrado. Éste impugna la dicotomía masculino/femenino refrendada por el pensamiento ilustrado denunciando su inadecuación con los presupuestos universalistas, al mismo tiempo que va sostener la necesidad de acordar a las mujeres el estatuto de individuos. ${ }^{6}$

Pero a pesar de los esfuerzos de este incipiente movimiento, la división simbólica de la humanidad y la asignación material de derechos y de espacios estaba ya trazada: la mujer en el espacio doméstico; el hombre, el ciudadano por antonomasia. En palabras de Genieviève Fraisse, la racionalidad moderna va a reservar a los hombres la creación de las leyes al tiempo que va a erigir a las mujeres en guardadoras de las costumbres. ${ }^{7} \mathrm{Si}$ bien, como recordé antes, en esa misma racionalidad moderna reposan los presupuestos de universalización de la subjetividad femenina, ésta se mantiene en estado de latencia hasta bien entrado el siglo XX, época en la que se generaliza la concesión del derecho a voto a las mujeres tras los 80 años de esfuerzo renovado del movimiento sufragista.

Es también un feminismo de raigambre liberal el que lidera la demanda sufragista. El movimiento sufragista, arropado intelectualmente por los trabajos de John Stuart Mill $^{8}$ y de su esposa Harriet Taylor, ${ }^{9}$ va a llamar la atención sobre las condicionantes sociales de la subordinación de la mujer; en particular, sobre la educación diferenciada

${ }^{6}$ El documento fundacional del feminismo es el texto de Mary Wollstonecraft que impugna la estrechez de la declaración de 1789 a través de su texto Vindicación de los derechos de la mujer de 1792. Puede consultarse el texto en castellano en Wollstonecraft, M., Vindicación de los derechos de la mujer (Edición de Marta Lois González) Editorial Istmo, Madrid, 2005.

${ }^{7}$ Cfr. Fraisse, Geneviève, La controverse des sexes.Presses universitaires de France, p. 98. En español puede consultarse también Fraisse, Geneviève, Los dos gobiernos: la familia y la ciudad, Ediciones CátedraUniversidad de Valencia-Instituto de la Mujer, Madrid, 2003.

${ }^{8}$ El siguiente párrafo ilustra su pensamiento: "todas las mujeres son educadas desde su niñez en la creencia de que el ideal de su carácter es absolutamente opuesto al del hombre: se las enseña a no tener iniciativa y a no conducirse según su voluntad consciente, sino a someterse y a consentir en la voluntad de los demás. Todos los principios del buen comportamiento les dicen que el deber de la mujer es vivir para los demás; y en el sentimentalismo corriente, que su naturaleza así lo requiere; debe negarse completamente a sí misma y no vivir más que para sus afectos, es decir, para los únicos afectos que se le permiten: los que se refieren al hombre con quien está unida o a los hijos que constituyen su vínculo nuevo e inquebrantable entre ella y un hombre. Si consideramos juntamente estas tres cosas: en primer lugar, la atracción natural entre los dos sexos; en segundo lugar, la entera dependencia de la mujer respecto de su marido, de manera que todo privilegio o placer que tiene es un don suyo o depende de su voluntad; y, por último, que el objeto principia de la solicitud humana, la consideración y todos los objetos de ambición social, sólo los puede pretender ella a través de su marido, vemos que hubiera sido un milagro que el objeto de ser atractiva no se hubiera convertido en el norte de la educación femenina y de la formación del carácter de la mujer". Véase, Stuart Mill, J. El sometimiento de la mujer (1869), en Stuart Mill, J. y Taylor Mill, H. Ensayos sobre la igualdad de los sexos, prólogo de Victoria Camps e Introducción de Alice B. Rossi, Antonio Machado Libros S. A. Madrid, 2000, pp. 161-162.

${ }^{9}$ La contribución de Harriet Taylor en el pensamiento de John Stuart Mill ha sido objeto de controversia. Primero negada rotundamente y, a partir de los años 70, aceptada de manera parcial, la figura de Harriet Taylor parece engrandecerse con los años. Para mayores antecedentes sobre la biografía y relación de ambos, así como de sus trabajos, puede consultarse Stuart Mill, J. y Taylor Mill, H. Ensayos sobre la igualdad de los sexos, cit., 2000. 
que reciben mujeres y hombres ${ }^{10}$ y sobre la errónea aplicación de los postulados de la racionalidad ilustrada en relación con las mujeres.

De ahí que el movimiento sufragista en su largo activismo ${ }^{11}$ no sólo haya buscado obtener para las mujeres la ciudadanía política formal sino, además, asegurarles el acceso a la educación y al trabajo. ${ }^{12}$ De hecho, ambas demandas se van a reforzar recíprocamente en el camino. El lento pero creciente acceso de las mujeres, primero a los niveles primarios de educación y posteriormente a las formaciones ligadas "a lo femenino" (la pedagogía, la enfermería), va a fragilizar la tesis de que éstas pertenecen naturalmente al hogar y va hacer cada vez más insostenible su preterición del dominio público. La demostración palmaria de que las mujeres pueden soportar incluso toda una economía, la aportaron las dos grandes guerras que aceleraron la aparición masiva de la mano de obra femenina. Después de la Segunda Guerra Mundial, en consecuencia, el sufragio femenino pasó de ser una excepción a ser la regla general.

El período posguerra marca un declive del movimiento feminista. Las mujeres deben retornar a sus hogares una vez que la fuerza de trabajo masculina regresa y, como es sabido, se produce un importante aumento de la natalidad. Todo ello va formar un caldo de cultivo suficiente para el surgimiento de lo que Betty Friedan denominó la Mística de la Feminidad, es decir, una confluencia de esfuerzos sociales, más o menos conscientes, tendentes a "re-encantar" a las mujeres con el espacio doméstico y cuyo eje será la exaltación de la maternidad. Las revistas femeninas, las series de televisión y las políticas gubernamentales buscarán dibujar una imagen idealizada del hogar y de las responsabilidades domésticas. El mensaje era claro: la recién conquistada ciudadanía política y el acceso a la educación y al trabajo no doméstico no debían interferir con las necesidades de administración del hogar y el cuidado de la familia. La tensión no tardó en instalarse. ${ }^{13}$

En este intersticio aparece el Segundo Sexo, el influyente libro de Simone de Beauvoir. En dicho texto la filósofa y escritora francesa retoma la tesis feminista de los orígenes sociales de la sumisión de la mujer. Es esta idea la que magistralmente sintetiza en su célebre frase "on ne naît pas femme, on le devient" (no se nace mujer, se llega a serlo). Beauvoir

${ }^{10}$ La educación diferenciada había sido abrazada por la ilustración. El propio Rousseau la promueve en su conocido texto El Emilio.

${ }^{11}$ En general, se fija como punto de partida de este movimiento la declaración de Seneca Falls (1848) en la que se reclama la ciudadanía plena de la mujer. Véase Miyares, A.; 1848 El manifiesto de Seneca Falls, disponible en versión electrónica, formato pdf, en http://webs.uvigo.es/pmayobre/textos/varios/seneca_falls.pdf, fecha de revisión 01/06/09.

12 Para una historia breve del feminismo puede verse Valcárcel, A.; La memoria colectiva y los restos del feminismo, CEPAL, Santiago de Chile, 2001.

${ }^{13}$ La imagen de que el trabajo implica una suerte de prostitución evocaba la ilegitimidad del ingreso de las mujeres al mercado de trabajo. En Europa, particularmente en Francia y en Inglaterra, se observa también un solapamiento de costumbres, una presencia de mujeres en el mercado de trabajo que aumenta paulatina, unida a roles de género en la familia y en la pareja que dan cuenta tanto de indicios de cambio como de núcleos de resistencia. Véase Sohn, A. M., "Los roles sexuales en Francia y en Inglaterra: una transición suave”, en Duby, G. y Perrot, M. (Dirs.) Historia de las mujeres. El siglo XX, Taurus, Madrid, 2006, pp. 127-157. Véase, además, Fraisse, G., Los dos gobiernos....cit.; pp. 44-57. 
explica cómo la alteridad sexual se ha edificado sobre la premisa de la inferioridad femenina que se traspasa tempranamente a la educación de las niñas para conformar una identidad diferenciada: el segundo sexo. ${ }^{14}$

La constatación de que la inferioridad de la mujer es un producto cultural va a ser vista por el nuevo movimiento feminista de los años sesenta como una muestra de la incapacidad de las estructuras patriarcales de producir la emancipación de la mujer. Si hasta este momento subsistía un optimismo moderado sobre las posibilidades de metamorfoseo del modelo universalista, a partir de este período, empezará a sugerirse que la lucha contra el patriarcado ${ }^{15}$ requiere un esfuerzo de descontaminación completo. Es decir, implica no sólo una crítica de sus presupuestos, estructuras e instituciones sino una superación del mismo, una "deconstrucción" en el sentido de reelaboración de un mundo compartido y no impuesto desde la masculinidad.

Con ello se pondrá las bases para la problematización expresa de la diferencia y la fundación del llamado feminismo de la diferencia, ${ }^{16}$ el cual subrayará que el análisis de la modernidad no puede prescindir del análisis de la diferencia sexual. ${ }^{17}$ Este enfoque resultará fortalecido por el desarrollo de los métodos de contracepción. La demanda de control del propio cuerpo, expresada a través del reclamo de la decisión sobre el aborto y la contracepción, va a contribuir notablemente a dar forma a la idea del sujeto corporeizado y a posicionar el discurso sobre la especificidad femenina.

En contraste con el feminismo liberal imperante (que adquirirá, en consecuencia, la etiqueta de feminismo de la igualdad), el feminismo de la diferencia expresa un rechazo, en algunos casos virulento (feminismo radical) respecto de la organización y cultura patriarcal y buscará reivindicar la singularidad femenina. Esto se hará a través de una redefinición de la feminidad, a veces centrada en la maternidad y/o en la afirmación

${ }^{14}$ En este sentido escribe: "Es una extraña experiencia para un individuo que se toma a sí mismo como sujeto de autonomía, de trascendencia, como un absoluto, descubrir en sí mismo a título de una esencia dada la inferioridad: es una extraña experiencia para aquel que se toma a sí mismo como el uno el ser revelado como la alteridad. Esto es lo que le pasa a la niña cuando haciendo el aprendizaje del mundo se descubre como una mujer. La esfera a la que pertenece está, por todos lados, cerrada, limitada, dominada por el universo masculino. No importa lo alto que se encumbre, lo lejos que se aventure, habrá siempre un techo por encima de su cabeza, muros que bloqueen su camino. Los dioses del hombre están en el cielo tan lejos que en realidad, para él, no hay dios; la niña vive entre dioses con rostro humano". Véase, Beauvoir, S. Le deuxième sexe II. L'expériencie vécue. Gallimard, 1976, p. 51. La traducción es mía.

${ }^{15}$ La noción de patriarcado se empieza a utilizar en esta época en el seno del feminismo radical con el sentido que le atribuimos contemporáneamente, es decir, como un sistema sociopolítico basado en la autoridad y liderazgo del varón, transformando su sentido inicial de gobierno del pater.

${ }^{16}$ El feminismo de la diferencia cubre un extenso crisol en que puede insertarse al feminismo radical estadounidense y su sucesor el feminismo cultural, el maternalismo y los feminismos de la diferencia francés e italiano. Todos exhiben diferentes matices, pero, en general, retoman la noción de especificidad o diferencia sexual.

${ }^{17}$ En palabras de Rosi Braidotti, "la cuestión de la Mujer se haya en el corazón mismo de la confusión de ideas que caracteriza a la modernidad; uno no puede formular la pregunta acerca de lo moderno sin plantear la interrogante sobre la diferencia sexual". Véase Braidotti, R. Feminismo, diferencia sexual y subjetividad nómade, Editorial Gedisa, 2004, p. 19. 
de la existencia de una ética específicamente femenina, otras con acento en la forma diferenciada en que mujeres y hombres vivencian la sexualidad.

Así, el rol de la diferencia sexual en la ciudadanía femenina, y más ampliamente en la construcción del sujeto, se va a transformar en un terreno en disputa provocando un verdadero cisma en el feminismo. Las críticas cruzadas se van a suceder hasta nuestros días. Mientras el feminismo de la igualdad critica al feminismo de la diferencia su intento de hacer tabla rasa del pasado y de pretender fundar una historia estrictamente femenina, el feminismo de la diferencia acusa al feminismo de la igualdad de ser complaciente y enajenar a la mujer en vez de liberarla. En este último registro Catharine MacKinnon llegará a afirmar que el feminismo liberal, en realidad, no es una teoría feminista sino simplemente la aplicación de los presupuestos liberales a la situación de las mujeres. Para MacKinnon "donde el feminismo liberal ve el sexismo básicamente como ilusión o mito que debe ser destruido, como inexactitud que debe ser corregida, el feminismo [radical] ve el punto de vista masculino como fundamento del poder masculino para crear el mundo a su propia imagen, la imagen de sus deseos, no sólo como producto final ilusorio". 18

Esta escisión elemental del pensamiento feminista grafica un problema que ha acompañado silente a la reivindicación de los derechos de las mujeres durante todo su devenir y que simplemente ha emergido: ¿La defensa de los derechos de la mujer se debe hacer en tanto mujeres o en tanto miembros de la especie humana? La cuestión no es simplemente retórica, como pretendo demostrar en las siguientes secciones.

\section{FEMINISMO y GÉNERO}

Me parece que, antes de continuar, es importante describir, aunque sea brevemente, la relación entre la noción de género y el feminismo. A este respecto tengo que confesar que no deja de sorprenderme la recurrencia de afirmaciones tales como "no soy feminista pero creo en la igualdad de género”. Las razones de lo que, en mi opinión, es una contradicción pueden rastrearse en la misma historia de la noción de género.

En la década de los 80 la voz género (gender) eclosiona y se populariza al punto de ingresar al lenguaje normativo, particularmente en el nivel internacional. Dicha expresión proviene del feminismo norteamericano y específicamente de los departamentos de investigación consagrados a los womens studies. Como explica Scott, en principio el término género denotaba un rechazo al determinismo biológico implícito en el empleo de términos tales como "sexo" y "diferencia sexual". ${ }^{19}$ Hoy día, sin embargo, la recuperación de la nociones de diferencia sexual y de sexo por parte de feminismo de la diferencia y la

18 Véase MacKinnon, C., Hacia una teoría feminista del Estado, Ediciones Cátedra-Universidad de Valencia-Instituto de la Mujer, p. 206.

19 Véase Scott, J, "El género: una categoría útil para el análisis histórico", en Amelang J.S. y Nash, M. Historia y género: las mujeres en la Europa Moderna y Contemporánea, Ed. Alfons el Magnànim, Valencia, 1990 , pp. 23-56. 
tesis de que el sexo también es construido socialmente promovida por ciertas teóricas en el ámbito de la filosofía queer, ${ }^{20}$ han provocado una cierta pérdida de protagonismo de la expresión género en el ámbito del discurso feminista. Curiosamente, en cambio, la noción de género ha engrosado su presencia en parcelas alejadas del feminismo, como ocurre por ejemplo, en el ámbito jurídico. ${ }^{21}$

Este auge de la expresión en otras esferas ligadas al estudio y reflexión sobre la situación de las mujeres, se explica por varios órdenes de causas. El primero está asociado al hecho de que el término género parece haberse desembarazado de la carga semántica negativa de un pasado ideológico-militante para adquirir un reconocimiento científico que a la teorización feminista, en cambio, le ha sido esquivo. De ahí vendría el "no soy feminista pero..." al que aludía con anterioridad.

En segundo lugar, porque como evoqué antes, la noción de género se incardinó (también debido a la acción de movimientos feministas) en el lenguaje normativo internacional, expandiéndose especialmente después de la Conferencia de Pekín, a las normas administrativas internas y a los estatutos legales referidos a la mujer (violencia doméstica, acoso sexual, interrupción del embarazo y contracepción, participación política, etc.). A partir de aquí, se ha vuelto frecuente, entonces, escuchar acerca de los planes de igualdad de género, de la violencia de género o incluso de las estadísticas de género. Como ya se habrá advertido, el precio de la popularización de la expresión es su vulgarización, es decir, la degradación de su significado hasta, en algunos casos, despojarle de todo carácter vindicativo, como ocurre cuando género se utiliza como un simple sinónimo de sexo o de mujeres.

La observación de tal vaciamiento de contenido ha llevado a algunas teóricas feministas a afirmar que actualmente no significa lo mismo "teorías de género" que feminismo. En este sentido, Alicia Miyares sostiene que las teorías de género mantendrían una actitud totalmente ambigua y en ocasiones de oposición, a la vindicación de la igualdad, a la participación política, a la emergencia de la individualidad. De ahí -según ella- que el vocablo género designaría apenas al colectivo de mujeres y, en el mejor de los casos, aludiría a una cultura femenina. ${ }^{22}$

Si bien la posición de Miyares no es descartable de entrada, creo que hay buenas razones para argumentar lo contrario, es decir, que la noción de género sigue vinculada al pensamiento feminista y que, todavía más, ha permitido proyectar tal teorización a dominios en que ésta resultaba desconocida o despreciada, como es el caso de la reflexión jurídica.

${ }^{20}$ Entre éstas destaca especialmente la filósofa estadounidense Judith Butler. Véase, en especial, Butler. J.; El género en disputa. El feminismo y la subversión de la identidad, Ed. Paidós, Buenos Aires, Argentina, 2001 y Deshacer el género, Paidós, Barcelona, 2006.

${ }^{21}$ A propósito de la forma en que la noción de género se enquista en el Derecho comunitario europeo, véase, Balaguer, M.L.; Mujer y Constitución. La construcción jurídica del género, Ediciones Cátedra-Universitat de Valencia, Instituto de la Mujer, Madrid, 2005, en especial pp. 57-88.

${ }^{22}$ Cfr. Miyares, A., Democracia feminista, Ediciones Cátedra-Universidad de Valencia, Instituto de la Mujer, Madrid, 2003, pp. 136 y 137. 
En primer lugar, la vulgarización semántica no es necesariamente sinónimo de banalización. Si eso fuera así habría que darse prisa en reemplazar una serie de expresiones capitales que han sufrido el mismo destino que género (libertad, democracia, derechos humanos, entre otras). Por el contrario, en muchos casos la vulgarización es síntoma de la difusión y arraigo de una idea-fuerza en una sociedad determinada. Esa idea permite dar cuenta de una nueva experiencia o expresa una nueva simbolización de experiencias preexistentes. En mi opinión, el núcleo semántico de la noción de género daría cuenta del fenómeno de subjetivación femenina explicitando su carácter inacabado. En otras palabras, su idea-fuerza es la de liberación o emancipación de las mujeres de una situación que es calificada de esclavitud, de incapacidad (jurídica) o de opresión. ${ }^{23}$

Por otra parte, los significados periféricos de expresiones ideológicas como género, democracia o derechos humanos son objeto de una continua reelaboración en el seno de sus matrices teóricas para que éstos capturen mejor las exigencias derivadas de la dialéctica entre su núcleo semántico (entendido como idea-fuerza) y los cambios sociales. Un análisis de los usos de la expresión género en el ámbito de los estudios de género ${ }^{24}$ revela que dicha expresión, en la mayoría de los casos, está lejos de ser aséptica y que sus presupuestos ideológicos y metodológicos arrancan del feminismo. Tanto es así, que independientemente de las distintas vertientes en que se divide actualmente el pensamiento feminista, puede afirmarse con rotundidad, que el feminismo es, en realidad, una teoría sobre el género. Aunque la cita es larga, las palabras de Seyla Benhabib son útiles para aclarar esta afirmación:

"Quiero definir dos premisas como constituyentes de la teorización feminista. Para la teoría feminista el sistema de género-sexo no es contingente sino un modo esencial en que se organiza, se divide simbólicamente y se experimenta la realidad social. Por sistema "género-sexo" entiendo la constitución e interpretación simbólica, sociohistórica de las diferencias anatómicas de los sexos. El sistema género-sexo es la cuadrícula a través de la cual el ser desarrolla una identidad materializada, un modo de ser en el propio cuerpo y de vivir el cuerpo. El ser se vuelve un yo en el hecho de que se toma de la comunidad humana un modo de experimentar psíquica, social y simbólicamente su identidad corporal. El sistema género-sexo es la cuadrícula a través de la cual las sociedades y las culturas reproducen individuos materializados".

${ }^{23}$ Geneviève Fraisse explica que las palabras "liberación” y "emancipación" han sido propias de la tradición feminista desde 1830 y que ambas van más allá de "mejorar la situación de la mujer”. La voz liberación, asociada a libertad, evoca una visión política, mientras que la expresión "emancipación”, de orden jurídico, implica el paso de una situación de minoría de edad a otra de mayoría de edad, es decir, de plena capacidad. Véase, Fraisse, G.; Los dos gobiernos; cit., pp. 44-49. La expresión “opresión” es utilizada, en cambio, por una tradición más tardía. En esta línea, por ejemplo, Iris Marion Young.

${ }^{24}$ Sobre los usos de la expresión género, véase, por ejemplo, Scott, Joan: "El género una categoría útil para el análisis histórico", cit., y Lamas, M.; "Usos, dificultades y posibilidades de la categoría de género", en El género y la construcción cultural de la diferencia sexual, México, UNAM, 1996, pp. 327-366. 
"Segundo, los sistemas género-sexo históricamente conocidos han contribuido a la opresión y la explotación de las mujeres. La tarea de la teoría crítica feminista es sacar a la luz este hecho y desarrollar una teoría que sea emancipadora y reflexiva y que pueda ayudar en sus luchas por superar la opresión y la explotación”. ${ }^{25}$

En un sentido similar se pronuncia Rosi Braidotti, exponente del feminismo de la diferencia, en el siguiente pasaje:

"Según el supuesto que sustenta mi visión de los estudios de las mujeres, el campo social es un sistema de fuerzas y representaciones semióticas y materiales que construyen el género como un término en proceso de normatividad y normalización. En un sistema de esta índole, el rol de la intelectual feminista consiste en mantener abiertas las áreas de indagación crítica, de crítica y de resistencia”.

La posición del feminismo respecto al género podría resumirse, en consecuencia, de la siguiente manera. Dentro del feminismo existe acuerdo en que: a) el sistema sexo/ género ha actuado históricamente como sistema de opresión respecto de las mujeres (y otros grupos); b) este es un sistema que se encuentra enraizado en mitos, simbolizaciones, representaciones, estructuras e instituciones sociales, y c) al feminismo le corresponde adoptar una actitud crítica y eventualmente remodeladora de la sociedad que permita la real emancipación las mujeres.

Las discrepancias de los distintos feminismos, y particularmente entre el feminismo de la igualdad y el feminismo de la diferencia, se extienden, en cambio, sobre temas relativos al impacto de la dicotomía público/privado en las relaciones de género, la construcción del sujeto político femenino o la forma en que el Estado influencia el sistema sexo/género. Son estas discrepancias las que, en mi opinión, están detrás de muchos de los casos de ambigüedad a los que alude Miyares.

Por último, conviene recordar que es esta estipulación básica de contenido de la expresión género la que permitió el traspaso desde los estudios académicos a las normas jurídicas, como lo demuestra el disputado contexto de adopción de los documentos adoptados en la Conferencia de Pekín ${ }^{26}$ y el desarrollo posterior de una familia de textos normativos internacionales y nacionales que continúan expresamente esta tradición.

${ }^{25}$ Benhabib, S., .El Ser y el Otro en la ética contemporánea. Feminismo, comunitarismo y posmodernismo, Editorial Gedisa, Barcelona, 2006, p. 175.

${ }^{26}$ Sobre este tema véase, por ejemplo, Subirats, M., "Cuando lo personal es político y es política", en Mariño, Fernando (Ed.), La protección internacional de la mujer tras la Conferencia de Pekín, Universidad Carlos III-BOE, Madrid, 1996, pp. 13-30. 


\section{LA DICOTOMÍA PÚBLICO/PRIVADO Y EL SUJETO POLÍ́TICO FEMENINO EN LA TEORÍA POLÍTICA FEMINISTA}

El pensamiento feminista postula que la dicotomía público/privado es creada por el pensamiento contractualista como un reflejo del binomio sociedad/naturaleza y que el pacto social es la fuente moderna de la sujeción femenina ${ }^{27}$. Y que la manera moderna de trazar la línea entre lo privado y lo público ha servido para relegar a las mujeres al ámbito familiar y de las tareas "naturalmente" femeninas, como las labores domésticas, la crianza y cuidado de los hijos, la atención de los enfermos y ancianos.

El hecho de que los límites entre ambas esferas no hayan sido objeto de una reflexión más profunda en cuanto a sus alcances por parte del pensamiento moderno y contemporáneo, parece ser un indicio de que la crítica feminista es plausible. En efecto, en el terreno jurídico, pese a la centralidad de la distinción privado/público, subsisten amplias zonas de penumbra. Por ejemplo, respecto de la tríada Estado-sociedad-individuo, no es claro si la sociedad se sitúa en el polo público o en el margen de lo privado. Tampoco es absolutamente prístino -contrariamente a lo que tiende a suponerse-que la familia pertenezca estrictamente a la esfera de lo privado. La insistencia con que los textos constitucionales declaran que la familia es la base de la sociedad y, más contemporáneamente, la cantidad de normas y capítulos en las constituciones destinados a regular su rol y los derechos y obligaciones de sus miembros, por un lado, y del Estado, por el otro, plantean dudas sobre la localización espacial de esta institución.

Puede pensarse, no obstante, que el núcleo de certeza de la dicotomía reside en su utilización en el marco de la teoría liberal. Para el liberalismo, lo privado designa las esferas de la vida de un individuo en la que toda interferencia estatal está prohibida y, contrario sensu, lo público hace referencia a esferas que son accesibles por el Estado de una forma más sencilla y legítimamente. Sin embargo, la distinción aporta apenas una frontera borrosa y movible.

Analizando esta cuestión, Seyla Benhabib ha establecido que en la tradición moderna habría tres utilizaciones de la expresión privacidad. La primera entendida como esfera de conciencia moral y religiosa, es decir, el terreno de los planes de vida o de los asuntos de la vida buena que, en la medida de ser considerados irresolubles desde el punto de vista racional, son administrados soberanamente por los propios individuos. Un segundo uso vinculado a las libertades económicas. Aquí, privacidad denotaría la no interferencia del Estado en el libre tráfico económico y en el mercado del trabajo. Y una tercera acepción en que privacidad equivale a esfera íntima y que engloba las relaciones de autoridad y de cuidado que se dan en el marco intrafamiliar. Según Benhabib, no sólo estos usos no son estrictamente equivalentes sino que los contextos designados en cada caso quedan

27 Además de los trabajos de Carole Pateman aquí citados, puede consultarse en el ámbito español Amorós, C.; Hacia una crítica de la razón patriarcal, Anthropos, Barcelona, 1991 y Cobo, R.; Fundamentos del patriarcado moderno. Jean Jacques Rousseau, Ediciones Cátedra, Universitat de València, Instituto de la Mujer, Madrid, 1995. 
afectados a diferentes principios. ${ }^{28}$ Así, por ejemplo, "mientras el ciudadano varón burgués batallaba por sus derechos de autonomía en las esferas religiosa y económica contra el Estado absolutista, sus relaciones en el hogar se definían por supuestos no consensuales e igualitarios". 29

La ambigua utilización de este binomio en la tradición liberal es, sin embargo, sólo la punta del iceberg. En sus cimientos yace una concatenación de premisas angulares del liberalismo que han sido objeto de una crítica más general por parte del feminismo. Este último ha impugnado la idea de que los seres humanos somos seres atomizados, antológicamente anteriores y superiores a la sociedad; la creencia de que los derechos fundamentales de las personas (particularmente de las mujeres) son protegidos mediante la garantía de no intrusión estatal, y la asunción de que la política y, en consecuencia, la ciudadanía, se agotan en una versión débil del principio de representación.

Esta crítica, sin embargo, en tanto precipitado entre la acción política y teórica del movimiento feminista, ha demorado en vertebrarse en su forma actual y no es pacífica en algunos de sus aspectos. La preocupación sobre la dicotomía público/privado empieza a adquirir centralidad en el pensamiento feminista a partir de la década del 60 . La idea dominante hasta entonces -también en los movimientos feministas- es que las mujeres estaban estrechamente ligadas a la esfera doméstica y que eran sus principales responsables. Así surge el famoso eslogan de "lo personal es político", que reivindica el control de la sexualidad y que establece el primer puente entre lo privado y lo público. Las implicaciones teóricas de esta intersección en lo concerniente al sujeto político femenino, han sido, en cambio, desarrolladas más tardíamente.

Sólo en la década de los 80 las feministas comienzan a considerar al Estado como objeto de análisis. Antes de eso, el feminismo contaba con una teoría sobre el poder (asimetrías de género) que, sin embargo, no se interrogaba especialmente por las vinculaciones entre ese poder (social) y Estado. A partir de esta época, empieza a tomar forma la idea de que la ciudadanía, como tal, no es neutra sino que, en realidad, es sexuada. ${ }^{30}$ Y sólo más recientemente -en la década de los 90- la atención del pensamiento feminista ha dejado de centrarse en los aspectos sociales y económicos de cuestiones que han sido consideradas como parte de lo privado (las relativas a los niños, la familia, la escolarización, el trabajo, la pornografía, el aborto, la violencia) para interesarse, además,

${ }^{28}$ Cfr. Benhabib, S., op. cit., pp. 126-127.

29 Ídem, p. 127.

${ }^{30}$ En este sentido, Silvia Walby ha criticado el conocido paradigma tripartito de la ciudadanía propuesto por Marshall. Como se sabe, este último establece que la ciudadanía se ha construido a través de tres dimensiones sucesivas: ciudadanía civil, ciudadanía política y ciudadanía social. Walby sostiene que Marshall ha descrito una ciudadanía civil primaria ligada a la libertad individual que -según el mismo autor expresa- incluye la libertad de la persona, la libertad de expresión, el derecho a la propiedad y el derecho a la justicia. Sin embargo, no ha reparado en que esos derechos no han sido obtenidos por las mujeres sino con posterioridad a la adquisición de la ciudadanía política, y algunos de ellos, como el derecho de recurrir a la justicia en caso de violencia masculina o la plena capacidad contractual, no son todavía completamente adquiridos.Véase Walby, S. "La citoyenneté est-elle sexuée?, en VVAA, Genre et politique. Débats et perspectives, Gallimard, París, 2000, pp. 51-82. 
en quién define en una sociedad los objetivos a alcanzar y los medios, es decir, más ampliamente en las prácticas democráticas. Este punto de inflexión es el que impulsa los planteamientos sobre repartición equilibrada del poder que están a la base de la noción de democracia paritaria.

Con todo, no es posible hablar de una evolución ni homogénea ni lineal de la teoría feminista en relación al binomio público/privado. Ciertamente, la propuesta feminista de politización de lo personal implica una redefinición de lo que, tradicionalmente, se ha considerado asuntos "privados" de la vida buena, los que comienzan a ser observados como cuestiones "públicas" de justicia. Implica, de otro lado, una "politización de la familia” y una reformulación del sujeto femenino en sus relaciones con la política; pero, como veremos, no necesariamente una respuesta común sobre los contornos y alcances de tales reconceptualizaciones.

La discrepancia parece entroncar, una vez más, con la valoración de la diferencia sexual. Así, por ejemplo, el pensamiento maternalista (uno de los llamados feminismos de la diferencia) ${ }^{31}$ propone un retorno al mundo de lo privado calificado como maternal, amante y virtuoso y, como contrapartida, el abandono de la esfera pública masculina vista como competitiva y ligada al Estado. ${ }^{32}$ Esta propuesta se articula sobre la base de la noción de ética del cuidado (etbics of care). Aunque omnipresente en un extenso repertorio discursivo y teórico en que podemos ubicar tendencias variopintas, este concepto debe su mayor sofisticación a los trabajos de Sara Ruddick y Jean Bethke Elshtain en el marco del feminismo maternalista, y desde aquí ha alcanzado una notable difusión. Para estas autoras, a través de la maternidad las mujeres adquirirían una actitud fundamental de protección y apoyo hacia lo vulnerable que se manifestaría en el trabajo compasivo de dar refugio, enfermería, alimentación, amistad, enseñar a los más jóvenes, atender a los frágiles ancianos. ${ }^{33} \mathrm{La}$ ética femenina del cuidado se opondría así a la ética de la justicia, típicamente masculina, caracterizada por la competencia, enfocada a lo público y construida sobre la base de una concepción abstracta de la justicia y del principio del "otro generalizado". En consecuencia, se postula una estrategia feminista de abandono de la política liberal

${ }^{31}$ El pesamiento maternalista es una corriente que suele situarse en el llamado feminismo de la diferencia y que exalta como positivos los valores tradicionales de la maternidad. En ocasiones suele confundírsele con enfoques feministas de otro corte debido a que éstos tratan el problema de la consideración social de la maternidad por la vía de la proposición de políticas públicas específicas. Para mayor información sobre esta confusión conceptual puede consultarse Toupin, L.: "Des "usages" de la maternité en l'histoire du feminisme”, Revista Recherches féministes, vol. 9, No 2, 1996, pp. 113-135, disponible en línea, formato pdf, en http://www.erudit.org/revue/rf/1996/v9/n2/057890ar.pdf, fecha de revisión 11/07/09.

32 En palabras de Mary Dietz, "el objetivo de las feministas "pro familia” es a la vez práctico y teórico: práctico en cuanto que ellas buscan quitarle a la Nueva Derecha la defensa de la familia (que acertadamente perciben como distorsionada y mistificadora del papel de las mujeres como madres y esposas); y teórico en cuanto intentan recuperar la maternidad como una dimensión de la experiencia de las mujeres y defenderla como necesaria tanto para la identidad de género como para la concientización política feminista". Véase Dietz, M., "Ciudadanía con cara feminista: el problema con el pensamiento maternal", en Debate Feminista, $\mathrm{N}^{\circ} 10$, septiembre de 1994, pp. 45-65.

${ }^{33}$ Véase Ferris, E.: Mujeres. Guerra y Paz. Traducción de Daniel Oliva, Life \& Peace Institute Uppsala, 2005 , p. 36. 
masculina y, la adopción, como contrapartida, de una política feminista centrada en lo privado; edificada sobre las virtudes del amor y de la intimidad y preocupada de las necesidades del "otro concreto", es decir, específicamente de la familia. ${ }^{34}$

Curiosamente, tanto el feminismo maternalista como el feminismo radical (generalmente antimaternalista) promueven, de forma abierta o implícitamente, un discurso de desactivación de la acción política-institucional femenina, aunque -claro está- por razones diversas. Si en el feminismo maternalista la apoliticidad reposa sobre una ética femenina superior que debe mantenerse a salvo del peligro de corrupción que entraña lo público, en el feminismo radical, el rechazo de la acción política descansa sobre una consideración del patriarcado -y del Estado por extensión- como construcciones esencialmente opresoras y, por tanto, no susceptibles de reconversión. ${ }^{35}$

En contraste, en la tradición ilustrada la diferencia es el producto (indeseado) del patriarcado y ambos -diferencia y patriarcado- deben ser reconstruidos con miras al logro de la igualdad. De ahí que no sorprenda que la demanda del feminismo liberal sea la reconceptualización de lo privado a la luz de los principios que informan lo público. En esta línea, Susan Moller Okin sostiene, por ejemplo, que "es únicamente en la medida en que una real igualdad es instaurada en la esfera doméstica de la familia, que el hecho de considerar esta esfera como privada es compatible con el respeto del derecho a la intimidad y con la seguridad física y socioeconómica de las mujeres y los niños”. ${ }^{36}$

Así las cosas, pareciera ser que es el feminismo liberal el que se presta de mejor manera para fundamentar las propuestas de participación política equilibrada entendidas como una radicalización de la universalidad que no se restringe al espacio de toma de decisiones políticas sino que alcanza al mercado de trabajo y a la esfera privada-familiar. ${ }^{37}$

${ }^{34}$ Para un comentario del pensamiento maternalista, véase Mouffe, C.: "Féminisme, citoyenneté et démocratie plurielle”, en VVAA, Genre et politique. Débats et perspectives. Gallimard, París, 2000. p. 178.

${ }^{35}$ En el marco del feminismo liberal, Chantal Mouffe ha criticado este aspecto de los trabajos de Carole Pateman. A juicio de Mouffe, el problema en la teoría de Pateman no es la deconstrucción de un patriarcado que se oculta bajo la forma de un individuo y un ciudadano aparentemente neutros -cuestión que Mouffe comparte-, sino en la falta de deconstrucción de la oposición hombre/mujer que Pateman tomaría como una oposición esencial. Según Mouffe, la perspectiva de Pateman descansa sobre el postulado de que existe una suerte de esencia específica en las mujeres en tanto que mujeres. Y este punto de partida esencialista implicaría también una propuesta política esencialista. Visto que la separación entre lo público y lo privado sería el momento fundador del patriarcado moderno y que el parto y la maternidad son presentados como la antítesis de la ciudadanía, todo aquello que es natural, es decir, parte de la diferencia sexual, no tendría cabida en lo público. Cfr Mouffe, Ch. Op. cit., pp. 182 y 183.

${ }^{36}$ Moller Okin, S. "Le genre, le public et le privé" en VVAA.; Genre et politique, cit., pp. 362-363. En el mismo sentido, Benhabib entiende, por su lado, que hay una "afinidad electiva" entre la teoría feminista (habría que agregar liberal) y la ética discursiva habermasiana, dado que ambas postulan que sólo relaciones de reciprocidad igualitaria, basadas en el respeto mutuo y el hecho de compartir todas las cargas por parte de las partes involucradas, pueden ser justas desde un punto de vista moral. Vid. Benhabib, op. cit. pp. 105-139.

${ }^{37}$ Nótese, por ejemplo, que la ley orgánica 3/2007 para la igualdad efectiva entre mujeres y hombres publicada en España el 22 de marzo de 2007 y el nuevo artículo 1 de la Constitución francesa consagran la igualdad y la paridad, respectivamente, en los ámbitos político, profesional y social (este último incluye a la familia). 
Se trata, en efecto, de una propuesta de transformación holística de las relaciones de género en clave de universalización de la igualdad en los planos privado y público.

Si bien, la propuesta liberal parece ambiciosa, registra históricamente ciertos éxitos bastante sonoros. La jurisprudencia estadounidense sobre el aborto ${ }^{38}$ es una muestra patente de las posibilidades de extensión de los principios aplicables a la vida pública a los ámbitos ligados a lo privado y, específicamente, a las decisiones de las mujeres sobre la reproducción. A partir de la década del 70, dicha jurisprudencia comienza a abandonar la noción de una intimidad de la familia, esto es, protectora de la familia como unidad; para avanzar hacia una intimidad en la familia que tutela la intimidad de cada miembro de ésta y específicamente de la mujer. Este cambio de rumbo está ligado a una progresiva influencia de las teorías feministas en la jurisprudencia norteamericana que se inicia con el caso Roe v. Wade en 1973 en el que la Corte Suprema de EE.UU. declara la inconstitucionalidad de las leyes contra el aborto por contravenir el derecho a la vida privada de las mujeres. ${ }^{39}$ Según Owen Fiss, desde una perspectiva constitucional esta jurisprudencia no descansa sobre la libertad, puesto que la Constitución de Estados Unidos no confiere a ningún individuo una libertad absoluta en dominio alguno y, por tanto, el deseo del Estado de proteger la vida del feto podría ser suficiente para limitar la decisión de abortar un embarazo. La decisión de la Corte Suprema, en contraste, sólo tendría un sentido constitucional si se parte de una interpretación del significado del derecho a elegir un aborto que considera la posición de las mujeres, es decir, como un medio de incrementar su igualdad. ${ }^{40}$

Existen, empero, otras evidencias y/o interpretaciones que pueden alimentar posturas escépticas en relación con las posibilidades de reconversión de las estructuras patriarcales. La propia MacKinnon proporciona una relectura menos optimista que la que propone Fiss sobre la jurisprudencia norteamericana en materia de aborto. MacKinnon afirma que esta jurisprudencia protege una libertad (control de la sexualidad) de la que, en la práctica, las mujeres carecen; impidiendo con ello un real debate político sobre las condiciones en las que efectivamente la sexualidad femenina se desarrolla. ${ }^{41}$

\footnotetext{
${ }^{38}$ Sobre el devenir de esta jurisprudencia, véase Shapiro, I. "El derecho constitucional al aborto en Estados Unidos: Una introducción”, en Revista Doxa, Cuadernos de Filosofía del Derecho, No 31, 2009, pp. 1-24.

${ }^{39}$ En lo medular, el fallo declara lo siguiente: "State criminal abortion laws, like those involved here, that except from criminality only a life-saving procedure on the mother's behalf without regard to the stage of her pregnancy and other interests involved violate the Due Process Clause of the Fourteenth Amendment, which protects against state action the right to privacy, including a woman's qualified right to terminate her pregnancy. Though the State cannot override that right, it has legitimate interests in protecting both the pregnant woman's health and the potentiality of human life, each of which interests grows and reaches a "compelling" point at various stages of the woman's approach to term". Véase US Corte Suprema, Roe v. Wade, 22 de enero de 1973, disponible en formato electrónico html en http://www.tourolaw.edu/Patch/ Roe/, fecha de revisión 04/06/09.

${ }^{40}$ Cfr. Fiss, O. ¿Qué es el feminismo?, en Doxa: Cuadernos de Filosofía del Derecho, No 14, 1993, pp. 322 y 323 .

41 Véase MacKinnon, op. cit., pp. 329-349.
} 
Como conclusión preliminar de lo tratado en esta sección, puede sostenerse que, a pesar de los matices de apreciación sobre el tratamiento de lo privado y lo público que fragmentan al pensamiento feminismo, éste, en general, no promueve la disolución de la dicotomía público/privado sino una relectura o una reconfiguración de la misma. Así las cosas, la necesidad de un ámbito privado, o como diría Virginia Woolf de "un cuarto propio", sigue, en general, estando presente en el planteamiento feminista a condición de su reconceptualización. En cambio, existen discrepancias sobre si la remodelación de este binomio con miras a la liberación de las mujeres supone o no la incardinación de éstas en el proceso político de toma de decisiones y en qué términos ${ }^{42}$ como veremos con más detalle en las secciones siguientes.

\section{La Redefinición de lo PÚblico. De las Representaciones de GÉNERO SOBRE LA POLÍTICA A LA POLÍTICA DE GÉNERO}

La teorización política feminista ha sido alimentada por estudios, particularmente sociológicos, que han revelado las conexiones existentes entre los roles de género en el hogar, la división sexual del trabajo y ciertas estructuras de segregación social implícitas en la escuela, el mercado o la política. A partir de ahí, el pensamiento feminista ha cuestionado la objetividad y neutralidad de los estudios tradicionales sobre la política.

Hasta que los estudios de género se vuelcan sobre la cuestión de la infrarepresentación política femenina en los años 80 , las relaciones entre política y género eran prácticamente ignoradas y la escasa presencia de mujeres era vista como parte de "la naturaleza de las cosas". ${ }^{43}$ En general, el discurso dominante postulaba que la magra presencia de mujeres en puestos de poder era una consecuencia de una falta de vocación política de éstas que, a su vez, se derivaba de factores personales, biológicos y/o de sus rasgos psicológicos. Tal hipótesis puede resumirse en la afirmación de que las mujeres tendrían una inclinación instintiva a permanecer en el espacio privado (léase la familia) y/o naturalmente serían menos competitivas. ${ }^{44}$

\footnotetext{
42 Sobre estas discrepancias teóricas, véase el interesante artículo de Rosa Cobo sobre las teóricas ilustradas y las teóricas de la diferencia en relación con la paridad. Cobo, R.; "Democracia Paritaria y sujeto político feminista”, Anales de la Cátedra Francisco Suárez, 36, 2002, pp. 29-44, disponible en línea, formato pdf, en http://www.ugr.es/ filode/pdf/contenido36_2.pdf, fecha de revisión 04/07/09.

${ }^{43} \mathrm{La}$ perspectiva de género en las ciencias sociales como, en general, en las otras ciencias tiene su carta de nacimiento en los años 60 y 70 con los llamados estudios feministas o de la mujer. En el caso francés Françoise Gaspard señala que una de las obras precursoras en esta materia ha sido la investigación de Maurice Duverger titulada La participation des femmes à la vie politique aparecida en 1955 y cuya elaboración fue encomendada por la Comisión de la condición de la Mujer de Naciones Unidas con ocasión de la adopción de la convención de Naciones Unidas sobre derechos políticos de la mujer de 1952. Véase Gaspard, F. Les travaux sur le vote et l'éligibilité. La situation française, Coloquio "Genre et politique", organizado por la Asociation Française de Sciencies Politiques, 30 y 31 de mayo de 2002, textos disponibles en el sitio de la AFSP http://www.afsp.msh-paris.fr/, en formato electrónico PDF, fecha de revisión 26/07/09.

${ }^{4}$ Estos discursos están, sin embargo, presentes en la política chilena según demuestra un estudio de Corporación Humanas, Véase Corporación Humanas, Encuesta Cámara de Diputados:
} 
A diferencia del postulado contractualista clásico que bosquejaba una ontología racional diferenciada entre mujeres y hombres, en la que éstas aparecían prácticamente carentes de voluntad o apresadas en una esencia femenina, ${ }^{45}$ el discurso explicativo contemporáneo no feminista matiza las apelaciones a una esencia femenina con la concurrencia de elementos volitivos. Tales elementos ensamblados generan un curioso resultado: el establecimiento de una regla general (la igualdad de acceso al poder entre hombres y mujeres) sobre la base de su excepción (la feble presencia femenina en puestos de poder). La socióloga francesa Françoise Gaspard hace notar que para este discurso una sola falda o un solo par de tacones que figuren en fotos ministeriales son considerados suficientes para probar que la igualdad de sexos ha triunfado. ${ }^{46}$

Sonia Dayan-Hezbrun, en la línea de los estudios de género, ofrece una manera distinta de interpretar el lento aumento de la presencia femenina en puestos de poder. Advierte que el destino excepcional de unas pocas ${ }^{47}$ no alcanza a alterar la regla de exclusión del conjunto. En otras palabras, el aumento reciente de la presencia femenina en puestos de poder no permite sostener que existe igualdad entre hombres y mujeres en lo concerniente al acceso a los puestos políticos; pero sí permite establecer que el ejercicio de altas funciones públicas por parte de las mujeres no pertenece al orden de lo absolutamente imposible. ${ }^{48}$

Esta última forma de observar la cuestión empieza a modularse en la década de los ochenta, época en que el pensamiento feminista acuña la expresión "techo de cristal". Esta expresión alude metafóricamente a un conjunto de mecanismos discriminatorios, poco visibles, que impiden o dificultan el acceso de las mujeres a las estructuras de

Opiniones en torno a mecanismos de corrección del déficit de representación femenina en cargos de elección popular, Santiago, 2006.

45 Geneviève Fraisse explica las particularidades de la racionalidad atribuida a las mujeres a partir de la revolución francesa. La filósofa francesa postula que esta racionalidad se va a construir de una manera tripartita: una razón de la especie, una razón moral y una razón práctica. La razón de la especie permitiría a la mujer comprender su identidad específica y, en consecuencia, no sirve ésta para satisfacer sus fines individuales sino que, por el contrario, está destinada servir a los fines de la "naturaleza femenina”. La razón moral, en tanto, vuelve a las mujeres capaces de una acción social propiamente femenina ligada a la maternidad educadora y que permanece anclada en las costumbres. Finalmente, la razón práctica permite a las mujeres situarse a medio camino entre el saber y el no saber, es decir, permite que éstas accedan al conocimiento de las tareas domésticas en sentido amplio (la "economía doméstica) sin que puedan aspirar a alcanzar el genio que es considerado típicamente masculino. Cfr. Fraisse, G. La controverse de sexes, Presses universitares de France, París 2001, pp. 98 y 99.

${ }^{46}$ Cfr. Gaspard, F., "La parité, pourquoi pas", en Revue Pouvoirs (revue fraçaise d'etudes constitutionelles et politiques), No 82, Femmes en Politique, 1997, p. 117. La traducción es mía.

${ }^{47}$ Dayan-Hezbrun explica que la presencia de mujeres en el poder, en muchos casos se explica sobre la base de una legitimidad carismática indirecta de origen masculino. En este sentido, la autora habla de una legitimidad "por la sangre" o "por la cama" para aludir, respectivamente, a las hijas de políticos (por ejemplo, Benanzir Butto o Indhira Ghandi) y a las viudas (por ejemplo, Violeta Chamorro y Corazón Aquino)”. Vid. Dayan-Hezbrun, S., "La mixité dans le politique", en VVAA: Genre et politique. Débats et perspectives. Gallimard, París, 2000, pp. 288-289.

48 Cfr. Ídem, p. 289. 
poder político. Evidentemente la apelación a esta particular "mano invisible" supone la inexistencia de barreras jurídicas explícitas de entrada a la actividad política que afecten determinadamente a mujeres.

A partir de entonces se comienza a señalar que las causas de la escasa presencia de mujeres en puestos de poder no son naturales sino que estarían ligadas a una socialización de género que subordina a las mujeres. Actualmente, una gran parte de las explicaciones que pueden recogerse en la literatura ligada a la temática reconoce que la feble presencia femenina en puestos de poder está determinada tanto por factores externos o estructurales como internos o, más bien, internalizados. ${ }^{49} \mathrm{La}$ dicotomía público/privado a la que me referí previamente, adquiere nuevamente relevancia explicativa para analizar esta cuestión. Desde el punto de vista estructural, los análisis de género constatan que la división sexual del trabajo genera tanto obstáculos estructurales ligados al uso del tiempo como patrones de socialización asimétrica de mujeres y hombres que se correlacionan con la baja presencia femenina en puestos de poder. ${ }^{50}$

Según el feminismo, todo lo anterior contribuye a la internalización de prejuicios que refuerzan la creencia de que el poder es eminentemente masculino. De acuerdo a este planteamiento, el sentido simbólico de las actividades desarrolladas por hombres y mujeres resulta definido heterónomamente, perfilándose dominios separados y jerarquizados, que son justificados y hasta sublimados mediante el argumento de la "complementariedad". El impacto de este prejuicio sería tal que el resultado es una verdadera "profecía autocumplida", poniendo en evidencia lo que Bourdieu denomina la "objetividad de la experiencia subjetiva de las relaciones de dominación". 51

${ }^{49}$ Véase, en este sentido, Astelarra, J. (comp.), Participación política de las mujeres, Centro de Investigaciones Sociológicas, Editores Siglo XXI de España, Madrid, 1990.

${ }^{50} \mathrm{El}$ examen de libros de texto escolares ha reflejado con frecuencia un panorama de reproducción en imágenes de la división de tareas por sexo en el que se muestra a la mujer en la casa mientras que el hombre hace historia fuera de ella. A esto se suma el hecho, también descrito en investigaciones, de que los docentes (tanto hombres como mujeres) manejan estereotipos sexistas acerca de la creatividad, el orden y la disciplina. Mientras entienden que orden y disciplina son atributos o virtudes propias de las mujeres, la creatividad es concebida como parte del patrimonio inherente a los hombres. En consecuencia, en la formación escolar básica los docentes exacerbarían una suerte de disposición natural femenina a la disciplina y al orden que tiende a llevar a las niñas a desconfiar de sí mismas y afecta su preparación para el liderazgo. Véase, por ejemplo, Garreta, N. y Careaga, P., Modelos masculino y femenino en los textos de EGB, Ministerio de Cultura/Instituto de la Mujer, Serie Estudios $N^{\circ} 14$, Madrid, 1987. En este estudio se concluye que existe una importante asimetría en cuanto al protagonismo que se otorga a los personajes masculinos y femeninos en los textos escolares, y los adjetivos y estereotipos que acompañan a unos y a otros y, en el caso chileno, Rosetti, J., La práctica pedagógica discrimina a las mujeres. Efectos sobre la vida adulta” en Barattini, C. (Ed.), Educación y género: Una propuesta pedagógica. Ediciones la Morada/ Ministerio de Educación, Santiago de Chile.

${ }^{51}$ Para Bourdieu lo simbólico, a diferencia de lo que suele entenderse, no es algo que se sitúe en el terreno de la fantasía o de lo espiritual como una suerte de opuesto a "lo real". De acuerdo al sociólogo francés, tal creencia es una distinción ingenua, propia de un materialismo primario. Cfr. Bourdieu, P., La domination masculine, Editions su Senil. París, 1998, 40. La traducción es mía. 
He aquí la gran aportación del pensamiento feminista a la teoría política: la desacralización del poder democrático a través de la denuncia de que éste descansa sobre una serie de elementos prototípicamente masculinos que son enmascarados por la metafísica moderna de la representación. ${ }^{52}$ Esta revelación no sólo refuta la supuesta apatía femenina como causal explicativa de la subrepresentación femenina sino que afianza la idea de que la democracia contemporánea, contrariamente a la doxa habitual, no es inclusiva. En efecto, si la masculinidad del poder es un presupuesto subyacente al modelo democrático, la exclusión femenina no necesita enunciarse en una regla explícita para producirse en los hechos. En otras palabras, si la igualdad descansa sobre el mito de la asexuación del poder (y del individuo), más que un proyecto realizable es un espejismo.

Este enfoque ha servido para poner en jaque el paradigma de la imparcialidad sobre el que se construyen las más influyentes teorías contemporáneas de la justicia. En este marco, Iris Young sostiene que visto que los agentes morales reales son particulares y no pueden apartar, sin más, su historia y afiliaciones particulares ni los intereses particulares sustanciales que están presentes en una decisión la imparcialidad, en su sentido fuerte, es imposible. Y si la imparcialidad es un ideal imposible resulta que las estructuras y asunciones que descansan sobre dicho principio pierden legitimidad, entre otras, el principio de representación y la neutralidad del Estado. Cabe interrogarse, entonces, sobre cuál es el verdadero rol de la imparcialidad en una sociedad democrática. Según Young, la insistencia en la imparcialidad tendría una función ideológica: legitima la toma de decisiones jerárquica y permite que el punto de vista de las personas privilegiadas aparezca como universal, es decir, permite universalizar lo particular. ${ }^{53}$ Es fácil ver que en el análisis de Young la imparcialidad actúa como un vector del patriarcado y de otras formas de opresión social.

Esta crítica al principio de imparcialidad, a poco andar, se transforma en un cuestionamiento a la capacidad del sistema democrático para asignar equitativamente todos los recursos, incluidos los asociados al propio poder político. Contrariamente a lo que pudiera pensarse, no sólo la versión liberal de la democracia sino también su homóloga social se situarán en la mira de los dardos del feminismo. De acuerdo a las feministas,

${ }^{52}$ Refrenda esta idea el cientista político Jean Vogel, quien señala que, dentro de las reglas del juego político, se encuentra el "principio de la distinción” entre los gobernados y los gobernantes. Este principio no sólo sintetizaría la relación entre el cuerpo electoral y sus representantes sino que, además, posibilitaría que estos últimos articulen sobre dicha distinción una verdadera profesión o carrera personal. Así, existiría un perfil preestablecido de caracteres necesarios y suficientes (culturales, sociológicos, antropológicos) para poder ejercer una función gobernante o representativa y una de las tareas esenciales de los partidos políticos sería precisamente asegurar una selección de postulantes al poder que garanticen la perennidad y la reproducción de este principio de distinción. Para Vogel uno de estos marcadores identitarios es el género, de tal suerte que pertenecer al sexo masculino sería una de las condiciones requeridas para poder ser admitido en el cuerpo de gobernantes. Cfr. Vogel, J. "La parité et les nouvelles figures de la citoyenneté”, en Jacqueline Martin (Dir.) La Parité. Enjeux y mise en oeuvre, Collecion Feminin \& masculin, Presses Universitaires du Mirail, Toulouse, 1998, p. 44.

${ }^{53}$ Cfr. Young, I., La justicia y la política de la diferencia, Ediciones Cátedra, Universitat de ValènciaInstituto e la Mujer, Madrid, 1990, pp. 168-196. 
si bien la democracia social aventaja a la versión liberal en su vocación transformadora, caería en el mismo error del marxismo al subsumir el género en la clase social, ${ }^{54}$ esto es, reduciría el problema de la igualdad a su dimensión económica, desatendiendo, en cambio, su dimensión sexuada o de reconocimiento. ${ }^{55}$ En consecuencia, para el feminismo ni el Estado liberal ni el Estado social sirven adecuadamente a los intereses y derechos de las mujeres. ${ }^{56}$ Ambos modelos no sólo no combaten la desigualdad de género sino que la refuerzan. El primero por una indiferencia reacia a interferir en las mores sociales, el segundo porque busca igualar a los sujetos en recursos sin afectar las asimetrías de género. En esta línea, por ejemplo, Nancy Fraser explica que las políticas del Estado de Bienestar han considerado a las mujeres primordialmente en su función doméstica-familiar, suministrando ayudas en los casos en que no existe un varón que provea de los medios de sustento, mientras que las políticas propiamente masculinas, esto es, dirigidas a los hombres, han estado dirigidas a insertarlos en el mercado de trabajo, como principal fuerza primaria laboral. ${ }^{57}$

Sin embargo, como apuntábamos antes, en la teorización feminista el acuerdo sobre el diagnóstico no implica, necesariamente, un consenso sobre el remedio. Ya comentamos que la asunción de que el poder y, por extensión, el Estado, son fundamentalmente masculinos es considerada por algunas ramas del feminismo como una evidencia de que este último es incapaz de promover con eficacia cualquier acción transformadora de los roles de género. La inserción de las mujeres en la estructura estatal implicaría, entonces, validar las mismas estructuras o prácticas en que se funda su subordinación. Para otras corrientes feministas (feminismo liberal y algunas teóricas del feminismo de la diferencia francés), en contraste, la inserción de las mujeres en las estructuras estatales es una forma de combatir esta masculinidad institucionalizada. Las estrategias de legitimación de esta última postura también son variopintas y encubren filiaciones teóricas diversas cuyo mestizaje, en algunos casos, puede revelarse problemático como demuestra la reciente experiencia francesa en relación con la paridad.

${ }^{54}$ Véase, en este sentido, el análisis de Catharine MacKinnon sobre marxismo y feminismo en MacKinnon, C., Hacia una teoría feminista del Estado, cit., pp. 23-109.

${ }^{55}$ En palabras de Alicia Miyares, la socialdemocracia si bien promueve el cambio institucional, limita la cohesión social a la igualdad distributiva sin percibir que aquella requiere, además, del reconocimiento. Cfr. Miyares, A., Democracia feminista, cit., p. 13.

${ }^{56}$ Para mayor información sobre las teorías feministas sobre el Estado, puede verse Masson, D. "Repensar L'État; nouvelles perspectivas féministes”, en Recherches féministes, vol. 12, N 1, 1999:5-24, disponible en formato pdf, en http://www.erudit.org/revue/RF/1999/v12/n1/058018ar.pdf, fecha de revisión 04/07/09.

57 Cfr. Fraser, N., “¿Qué tiene de crítica la teoría crítica? Habermas y la cuestión del género”, en Benhabid, S. y Cornella, D., Teoría feminista y teoría crítica. Ensayos sobre la política de género en las sociedades del capitalismo tardío. Edicions Alfons el Magnànim, Generalitat Valenciana, Valencia, 1990, pp. 78 y 79. En el mismo sentido se pronuncia Carole Pateman. Véase Pateman, C., "El Estado de Bienestar Patriarcal", en Contextos, Año 2, N 5, Universidad Católica del Perú, Lima, 2000. 


\section{LAS CONTRADICCIONES DEL SUJETO POLÍTICO FEMENINO.} LA PARIDAD EN LA TEORÍA Y EN LA PRÁCTICA

En 1992 -y paralelamente a la celebración de la cumbre de Atenas- se publica Au Pouvoir citoyennes! Liberté, egalité et parité. ${ }^{58}$ En este texto-que se convertirá en un verdadero manifiesto de la causa feminista en Francia- se utiliza por primera vez la expresión paridad. Esta expresión dará origen a un verdadero movimiento político que reclamará el reconocimiento normativo de la dualidad sexual de la humanidad y la correlativa repartición equilibrada en el poder. A los efectos de este trabajo, conviene detenerse sobre las bases de su éxito.

Según Joan Scott, la gran innovación de este movimiento consiste en que-contrariamente a los femeninos precedentes- no se exige a las mujeres conformarse a una figura neutra (históricamente masculina) ni tampoco encarnar una identidad femenina distinta. En lugar de eso, es el individuo abstracto que es definido de nuevo a objeto de que sea realmente inclusivo e integre a las mujeres. El movimiento por la paridad, a diferencia de sus predecesores, no interpela la idea misma de ciudadanía abstracta ni denuncia la no pertinencia del cuerpo en la definición de representación ni tampoco las condiciones mismas de la abstracción, sólo insiste en la dualidad anatómica de la humanidad. En este marco, la paridad es (simplemente) la manera a través de la cual la representación refleja dicha dualidad sexual, es decir, inserta la naturaleza en lo político.

Sobre la base de este aparato conceptual, el movimiento por la paridad pudo sortear el obstáculo proveniente de la centralidad de las nociones de pueblo y de representación en la tradición universalista francesa ${ }^{59}$ y consiguió los apoyos suficientes para catalizar algo que, de ordinario, resulta más complicado que establecer una ley, esto es, acordar una reforma a la Constitución. ${ }^{60}$ Este éxito está, sin duda, ligado a una de las grandes

${ }^{58}$ Su traducción al castellano es ¡Al poder ciudadanas! Libertad, igualdad y paridad. Véase Gaspard, F., Servan-Schreiber, C. y Le Gall, A., Au Pouvoir citoyennes! Liberté, egalité et parité, Senil, París, 1992.

59 Tales nociones fundamentaron la decisión de 1982 del Consejo Constitucional que impidió la instauración de artículo de un proyecto de ley que establecía una cuota electoral de alrededor de $20 \%$. Para fundar su decisión, el Consejo cita los términos de los art. 3 de la Constitución y 6 de la Declaración de 1789, y deduce que la "calidad de ciudadano abre el derecho de voto y la elegibilidad en condiciones idénticas a todos quienes no son excluidos por razón de edad, incapacidad o nacionalidad, o por una razón que tienda a preservar la libertad del elector o la independencia del elegido, que esos principios de valor constitucional se oponen a toda división por categorías de los electores o de los elegibles y que esto es así para todo sufragio político. Con esta decisión, el Consejo Constitucional no sólo sorprendió por haber utilizado por primera vez la facultad de declarar inconstitucional una disposición no impugnada en el requerimiento, sino, además, porque ni siquiera consideró que el preámbulo de la Constitución francesa señala expresamente que "la ley garantiza a la mujer en todos los dominios, derechos iguales a los de los hombres". Véase Consejo Constitucional, Decisión No 82-146, de 18 de noviembre 1982. Para mayores antecedentes sobre la jurisprudencia francesa en materia de igualdad, puede verse VVAA, Conseil d'Etat: Sur le principe d'égalité. Extrait du rapport public 1996, La Documentation française, París 1998.

${ }^{60}$ Véase la Ley Constitucional No $99-569$ de 8 de julio de 1999 relativa a la igualdad entre mujeres y hombres que introdujo la siguiente disposición en el art. 3 de la Constitución de 1958: "la ley favorece el acceso igualitario de mujeres y hombres a los mandatos electorales y funciones electivas”. Esta disposición 
fortalezas del movimiento por la paridad: su habilidad para condensar un postulado complejo en una idea evidente y simple (la humanidad está formada por dos sexos). Sin embargo, esta misma fortaleza ha ocultado una de sus mayores debilidades: la problemática construcción teórica de la propia noción de paridad. Es esta paradoja a la que la filósofa francesa Geneviève Fraisse alude cuando insiste en que "la paridad es verdadera en la práctica pero falsa en la teoría”. ${ }^{61}$

En su estudio sobre las estrategias de legitimación de la paridad en Francia, Bereni y Lépinard listan los siguientes argumentos utilizados por miembros del movimiento y parlamentarios pro-paridad: a) un argumento ligado al principio de igualdad; b), un argumento que relaciona el aumento de la presencia de mujeres en el poder con una mejor defensa de sus intereses específicos de género; c). Un argumento que entiende que la presencia femenina permite devolver a la representación democrática su sentido original inclusivo corrigiendo la parcialidad de una representación masculina y, por tanto, incompleta, y d) un argumento que concierne a las competencias que supuestamente las mujeres podrían aportar a la política, en cuanto mujeres, y que permitirían un mejoramiento de la política. ${ }^{62}$ Un examen atento de estos argumentos revela que responden a diversas tradiciones teóricas sobre el sujeto político femenino. Mientras a) y c) pueden asociarse al feminismo de la igualdad, b) y d) están vinculados al pensamiento sobre la diferencia.

La hibridación de argumentos puede explicarse por el hecho de que el movimiento paritarista francés implicó, también, una hibridación de feminismos. Se inicia como un movimiento liderado por el feminismo liberal para ser objeto de una apropiación tardía del feminismo de la diferencia, cuya cara más visible en Francia es la filósofa Sylviane Agacinski. ${ }^{63}$ Las consecuencias de esta hibridación no son pacíficas tanto a nivel teórico como práctico.

Si bien es posible concebir la igualdad como una abstracción situada, morigerando con ello los rigores de la tradición liberal clásica y permitiendo la convivencia armoniosa entre igualdad y diferencia como lo hacen varias exponentes del feminismo de la igualdad, ${ }^{64}$ las pensadoras de la diferencia consideran, en cambio, que la diferencia sexual es una diferencia esencial. Esto implica que, en general, para estas últimas feministas, el reconocimiento de la diferencia no se satisface con la mera contextualización del sujeto sino que supone un reconocimiento de identidad, es decir, el reconocimiento de los grupos como una realidad ontológicamente distinta a la mera agrupación de individuos. Esta

ha sido modificada por la Ley Constitucional $N^{o} 2008-724$ de 2008 que traslada dicha norma al art. $1^{\circ}$ y la amplía a las responsabilidades profesionales y sociales.

${ }^{61}$ Esta expresión es acuñada por la autora en una conferencia ha sido repetida en varios de sus trabajos posteriores al establecimiento de las leyes sobre la paridad.

${ }^{62}$ BereniI, L. y Lepinard, E., "Les femmes ne sont pas une catégorie Les stratégies de légitimation de la parité en France”, Revue française de science politique, vol. 54 N ${ }^{\circ}$ 1, febrero de 2004, pp. 71-88.

${ }^{63}$ Para mayor información sobre el pensamiento de esta filósofa sobre este tema, véase Agacinski, S., Política de sexos, Madrid, Editorial Taurus, 1998, y Le passeur de temps. Modernité et Nostalgie, Seuil, París, 2000 .

${ }^{64}$ En este sentido, Benhabib y Mouffe, por ejemplo. 
forma de comprender la diferencia es, como ya se habrá advertido, difícilmente compatible con el feminismo de la igualdad que - para no de perder su raigambre liberal-requiere seguir anclado en el individuo y considerar a los sujetos como ontológicamente iguales, lo que, a su vez, supone cierto apego al mecanismo de la abstracción.

Curiosamente, la solución de estas tensiones en el seno del movimiento paritarista arroja un perfecto empate entre tradiciones opuestas. La tensión entre abstracción y concreción se resuelve a favor de la tradición liberal. Los paritaristas reiteran que la paridad no implica un reemplazo del individuo abstracto por un individuo concreto, sólo implica el paso de un individuo abstracto asexuado a un individuo abstracto sexuado. La tensión igualdad-diferencia, en cambio, se zanja a favor de esta última pero conjurando el peligro del comunitarismo. Así se insistirá que las mujeres no son un grupo cualquiera (como los judíos, los negros, los inmigrantes, etc.) sino la mitad de la humanidad. La diferencia sexual, entonces, no es una diferencia fungible, equivalente a cualquier otro atributo o situación. La diferencia sexual es esencial e irreductible.

Pero una verdadera síntesis de opuestos requiere más que piruetas dialécticas. Implica resignificaciones derivadas de nuevos procesos de estipulación de contenido. Es dudoso que la paridad a la francesa suponga la conclusión de un proceso de resignificación de la diferencia sexual que pueda refundir dos tradiciones que han separado al propio feminismo. Diría, en cambio, que es más probable que sea un eslabón que se suma a la intrincada cadena de relaciones entre igualdad (o tipos de igualdad) y diferencia (o tipos de diferencia) y aporta nuevos elementos para la reflexión.

En efecto, la reciente experiencia francesa demuestra que las distintas aproximaciones sobre el rol de la diferencia sexual en la construcción teórica de la ciudadanía; producen también consecuencias diversas en relación con el tratamiento de otras diferencias, configurando verdaderos puzzles sobre la igualdad. La casualidad quiso que la leyes de paridad se discutieran paralelamente a la ley del PACS (Pacte civil de solidaritê) dirigida a regular las uniones de hecho, incluyendo aquellas de parejas homosexuales. ${ }^{65}$ Los debates cruzados terminaron afectando la reivindicación homosexual, que -ya se habrá advertido- también está apresada en el dilema igualdad/diferencia. Así, la sexuación del pueblo en una dualidad femenina/masculina promovida por la paridad, fue interpretada por algunos diputados franceses como la evidencia de una verdad absoluta: la heterosexualidad normativa. El resultado fue que, en un caso, la diferencia sexual actuó como factor de inclusión de las mujeres en la política mientras que, en el otro, la diferencia (esta vez de inclinación sexual) se transformó en un factor de exclusión del matrimonio y, por extensión, del derecho a fundar familia. ${ }^{66}$

Alguien podría pensar que el impacto negativo de la aproximación paritarista respecto de la demanda de colectivos homosexuales es meramente conyuntural. La cuestión es,

${ }^{65}$ En realidad, inicialmente se buscaba regular la situación de las parejas homosexuales pero para seguir fieles al universalismo republicano francés y, sobre todo, para que el PACS no se considerara un equivalente homosexual del matrimonio, se prefirió incluir también en la regulación a las parejas heterosexuales.

${ }^{66}$ El PACS regula los aspectos patrimoniales de las uniones de hecho y excluye expresamente el derecho a la parentalidad a través de la adopción. 
sin embargo, discutible. Los trabajos de ciertas teóricas de la diferencia implicadas en el movimiento paritarista sugieren, en contraste, que se trata de una anudación de causaefecto. Las palabras de Sylviane Agacinski -criticando el pensamiento liberal- resultan extremadamente esclarecedoras sobre la conexión entre la concepción de la humanidad como (hetero)sexuada y el rechazo de la demanda homosexual de parentalidad:

"Ceux qui, par crainte d'un prétendu "naturalisme", récusent toute inscription de la différence des sexes dans le droit se précipitent aveuglément dans les bras de la technique, comme si elle devait desormais, à elle seule, fonder le droit. Avec une certaine cohérence, ce son les mêmes qui condamnent la parité et légitiment le droit aux enfants "biologiques ou adoptés" pour les couples du même sexe". ${ }^{67}$

El tratamiento de la diferencia de sexo en la teoría política y en los derechos humanos continúa, al parecer, siendo un terreno movedizo lleno de obstáculos y riesgos. Si el riesgo más evidente del postulado de que la diferencia sexual no debiera ser relevante en política es la mantención de la preterición de las mujeres del dominio político, el riesgo más apremiante de la reivindicación de la diferencia sexual como rasgo político es la esencialización de los sexos.

Creo que con este repaso simplemente ejemplar de algunas de las discrepancias del feminismo en relación a la diferencia sexual, al binomio público/privado, el poder y al Estado, es posible concluir que la introducción de la categoría del género al ámbito jurídico no resuelve el problema de la ciudadanía femenina, sino que, al contrario, abre las puertas a su problematización. Sin duda, el valioso aporte del pensamiento feminista resulta crucial para emprender esta tarea.

\section{BIBLIOGRAFÍA}

Agacinski, S., Política de sexos, Madrid, Editorial Taurus, 1998.

Agacinski, S., Le passeur de temps. Modernité et Nostalgie, Seuil, París, 2000.

Agacinski, S., Engagements, Ediciones Seuil, París, 2007.

Amorós, C., Hacia una crítica de la razón patriarcal, Anthropos, Barcelona, 1991.

Astelarra, J. (comp.), Participación política de las mujeres, Centro de Investigaciones Sociológicas, Editores Siglo XXI de España, Madrid, 1990.

Balaguer, M.L., Mujer y Constitución. La construcción jurídica del género, Ediciones Cátedra-

Universitat de Valencia, Instituto de la Mujer, Madrid, 2005.

Beauvorr, S., Le deuxième sexe II. L'expériencie vécue. Gallimard, 1976.

67 "Los que por miedo de un presunto naturalismo rechazan toda inscripción de la diferencia de sexo en el derecho, se precipitan ciegamente en los brazos de la técnica, como si ella debiera, sólo ella, fundar desde ahora el derecho. Con cierta coherencia, son los mismos que condenan la paridad y legitiman el derecho a los niños "biológicos u adoptados" para (por parte de) las parejas homosexuales", la traducción es mía. Vid. Agacinski, S. Engagements, Ediciones Seuil, París, 2007, p. 38. 
Benhabib, S., El Ser y el Otro en la ética contemporánea. Feminismo, comunitarismo y posmodernismo, Editorial Gedisa, Barcelona, 2006.

Bereni, L. y LÉPINARD, E., "Les femmes ne sont pas une catégorie Les stratégies de légitimation de la parité en France”, Revue française de science politique, vol. 54 N ${ }^{\circ}$, febrero de 2004, pp. $71-88$.

Borderías, C. (Ed.), Joan Scott y las políticas de la historia, Editorial Icaria, Madrid, 2006.

Bourdieu, P., La domination masculine, Editions su Senil. París, 1998, 40.

Braidotti, R. Feminismo, diferencia sexual y subjetividad nómade, Editorial Gedisa, 2004.

Butler. J., El género en disputa. El feminismo y la subversión de la identidad, Ed. Paidós, Buenos Aires Argentina, 2001.

Butler. J., Deshacer el género, Paidós, Barcelona, 2006.

Сово, R., Fundamentos del patriarcado moderno. Jean Jacques Rousseau, Ediciones Cátedra, Universitat de València, Instituto de la Mujer, Madrid, 1995.

Сово, R., “Democracia Paritaria y sujeto político feminista”, Anales de la Cátedra Francisco Suárez, 36, 2002, pp. 29-44.

Corporación Humanas, Encuesta Cámara de Diputados: Opiniones en torno a mecanismos de corrección del déficit de representación femenina en cargos de elección popular, Santiago, 2006.

Dayan-Hezbrun, S., "La mixité dans le politique", en VVAA: Genre et politique. Débats et perspectives. Gallimard, París, 2000, pp. 288-289.

Dietz, M., "Ciudadanía con cara feminista: el problema con el pensamiento maternal”, en Debate Feminista, No 10 , septiembre de 1994 , pp. 45-65.

Ferris, E., Mujeres. Guerra y Paz. Traducción de Daniel Oliva, Life \& Peace Institute Uppsala, 2005.

Fiss, O., ¿Qué es el feminismo?, en Doxa: Cuadernos de Filosofía del Derecho, N ${ }^{\circ}$ 14, 1993 , pp. 319-336.

Fraisse, G., La controverse des sexes. Presses universitaires de France, París, 2001.

Fraisse, G., Los dos gobiernos: la familia y la ciudad, Ediciones Cátedra-Universidad de ValenciaInstituto de la Mujer, Madrid, 2003.

Fraser, N., “¿Qué tiene de crítica la teoría crítica? Habermas y la cuestión del género”, en Benhabid, S. y Cornella, D.: Teoría feminista y teoría crítica. Ensayos sobre la política de género en las sociedades del capitalismo tardío. Edicions Alfons el Magnànim, Generalitat Valenciana, Valencia, 1990, pp. 49-88.

Garreta, N. y Careaga, P., Modelos masculino y femenino en los textos de EGB, Ministerio de Cultura/Instituto de la Mujer, Serie Estudios No 14 , Madrid, 1987.

Gaspard, F., Les travaux sur le vote et l'éligibilité. La situation française, Coloquio "Genre et politique", organizado por la Asociation Française de Sciencies Politiques, 30 y 31 de mayo de 2002, textos disponibles en el sitio de la AFSP http://www.afsp.msh-paris.fr/, en formato electrónico PDF, fecha de revisión 26/07/09.

Gaspard, F., "La parité, pourquoi pas", en Revue Pouvoirs (revue fraçaise d'etudes constitutionelles et politiques), N 82, Femmes en Politique, 1997.

Gaspard, F. (con Servan-Schreiber, C. y Le Gall, A., Au Pouvoir citoyennes! Liberté, egalité et parité, Senil, París, 1992.

Lamas, M.; “Usos, dificultades y posibilidades de la categoría de género”, en El género y la construcción cultural de la diferencia sexual, México, UNAM, 1996, pp. 327-366.

MacKinnon, C., Hacia una teoría feminista del Estado, Ediciones Cátedra-Universidad de ValenciaInstituto de la Mujer.

Masson, D., "Repensar L'État; nouvelles perspectivas féministes”, en Recherches féministes, vol. 12, $\mathrm{N}^{\mathrm{o}}$ 1, 1999:5-24, disponible en formato pdf, en http://www.erudit.org/revue/RF/1999/v12/ n1/058018ar.pdf, fecha de revisión 04/07/09. 
Miyares, A., Democracia feminista, Ediciones Cátedra-Universidad de Valencia, Instituto de la Mujer, Madrid, 2003, pp. 136 y 137.

Miyares, A., 1848 El manifiesto de Seneca Falls, disponible en versión electrónico, formato pdf, en http://webs.uvigo.es/pmayobre/textos/varios/seneca_falls.pdf, fecha de revisión, 01/06/09.

Moller Okin, S., "Le genre, le public et le privé" en VVAA.; Genre et politique. Débats et perspectives. Gallimard, París, 2000, pp. 362-363.

Mouffe, CH., "Féminisme, citoyenneté et démocratie plurielle", en VVAA, Genre et politique. Débats et perspectives. Gallimard, París, 2000. pp. 167-196.

Pateman, C., El contrato sexual, Arthropos, Barcelona, 1995.

Pateman, C., "El Estado de Bienestar Patriarcal" en Contextos, Año 2, Nº 5, Universidad Católica del Perú, Lima, 2000.

Rosetti, J., "La práctica pedagógica discrimina a las mujeres. Efectos sobre la vida adulta", en Barattini, C. (Ed.), Educación y género: Una propuesta pedagógica. Ediciones La Morada/ Ministerio de Educación, Santiago de Chile.

Scotт, J., "El género: una categoría útil para el análisis histórico”, en Amelang J. S. y Nash, M. Historia y género: las mujeres en la Europa Moderna y Contemporánea, Ed. Alfons el Magnànim, Valencia, 1990, pp. 23-56

ScotT, J., La citoyenne paradoxale. Le féministes françaises et les droits de l'homme, Biblioteque Albin Michel, Histoire, París, 1998.

Scott, J., Parité! L'universel et la différence des sexes, Bibliothèque Albin Michel idées, París, 2005.

Shapiro, I., "El derecho constitucional al aborto en Estados Unidos: Una introducción", en Revista Doxa, Cuadernos de Filosofía del Derecho, No 31, 2009, pp. 1-24.

SoHn, A. M., "Los roles sexuales en Francia y en Inglaterra: una transición suave”, en Duby, G. y Perrot, M. (Dirs.) Historia de las mujeres. El siglo XX, Taurus, Madrid, 2006, pp. 127-157.

Stuart Mill, J., El sometimiento de la mujer (1869), en Stuart Mill, J. y Taylor Mill, H. Ensayos sobre la igualdad de los sexos, prólogo de Victoria Camps e Introducción de Alice B. Rossi, Antonio Machado Libros S.A. Madrid, 2000, pp. 145-261.

Subirats, M., "Cuando lo personal es político y es política", en Mariño, Fernando (Ed.), La protección internacional de la mujer tras la Conferencia de Pekín, Universidad Carlos III-BOE, Madrid, 1996, pp. 13-30.

Toupin, L., "Des "usages" de la maternité en l'histoire du feminisme", Revista Recherches féministes, vol. 9, $\mathrm{N}^{\circ}$ 2, 1996, pp. 113-135, disponible en línea, formato pdf, en http://www.erudit. org/revue/rf/1996/v9/n2/057890ar.pdf, fecha de revisión 11/07/09.

UNIÓN INTERPARLAMENTARIA. Les femmes en politique: 60 ans en rétrospective (donnés valables au 01.02.2006), disponible en formato pdf en http://www.ipu.org/pdf/publications/wmninfokit06_fr.pdf, fecha de revisión 16.07.09.

VALCÁrCel, A., La memoria colectiva y los restos del feminismo, CEPAL, Santiago de Chile, 2001.

Vogel, J,. "La parité et les nouvelles figures de la citoyenneté", en Jacqueline Martin (Dir.) La Parité. Enjeux y mise en oeuvre, Collecion Feminin \& masculin, Presses Universitaires du Mirail, Toulouse, 1998, pp. 41-50.

VVAA, Conseil d'Etat: Sur le principe d'égalité. Extrait du rapport public 1996, La Documentation française, París 1998.

Walby, S., "La citoyenneté est-elle sexuée?, en VVAA, Genre et politique. Débats et perspectives, Gallimard, París, 2000, pp. 51-82.

Wollstonecraft, M., Vindicación de los derechos de la mujer (Edición de Marta Lois González) Editorial Istmo, Madrid, 2005.

Young, I., La justicia y la política de la diferencia, Ediciones Cátedra, Universitat de ValènciaInstituto de la Mujer, Madrid, 1990. 